Journal of World Englishes and Educational Practices (JWEEP)

ISSN: 2707-7586

DOI: 10.32996/jweep

Website: https://al-kindipublisher.com/index.php/jweep/index

\title{
Hybridity in Nepalese English
}

Shankar Dewan ${ }^{1 *}$ and Chandra Kumar Laksamba, PhD ${ }^{2}$

${ }^{1}$ Lecturer, Department of English, Sukuna Multiple Campus, Sundarharaincha, Morang, Nepal

${ }^{2}$ Adjunct Professor, Faculty of Social Sciences and Education, Nepal Open University, Manbhawan, Lalitpur, Nepal

Corresponding Author: Shankar Dewan, E-mail: dewanms4@gmail.com

ARTICLE INFO

Received: December 3, 2020

Accepted: December 11, 2020

Volume: 2

Issue: 6

DOI: 0.32996/jweep.2020.2.6.2

\section{KEYWORDS}

Nepalese English, language contact, hybridity, bilinguals' creativity, nativization

\section{ABSTRACT}

With its unprecedented spread globally, English has been diversified, nativized, and hybridized in different countries. In Nepal, English is code-mixed or hybridized as a result of its contact with the local languages, the bilinguals' creativity, and the nativization by Nepalese English speakers. This qualitative content analysis paper attempts to describe hybridity in Nepalese English by bringing the linguistic examples from two anthologies of stories, two novels, five essays and two articles written in English by Nepalese writers, one news story published in the English newspaper, advertisements/banners, and diary entries, which were sampled purposively. The present study showed that hybridity is found in affixation, reduplication, compounding, blending, neologisms, and calques. Pedagogically, speakers of Nepalese English can utilize linguistic hybridization as a powerful tool to nativize English in the local contexts, exhibit hybrid identities and linguistic co-existence, exercise their bilingual linguistic creativity, reduce their linguistic anxiety, and maximize the linguistic economy.

\section{Introduction}

Nepal is a plurilingual country, a homeland to a total number of 123 languages spoken as mother tongues (Central Bureau of Statistics [CBS], 2014), which has reached in 129 after the addition of six languages (Awasthi, 2020), and where $0.01 \%$ people of the total population speak English as a mother tongue and $0.30 \%$ speak it as the second language (CBS, 2014). This census record dramatically varies from Crystal's (2003) estimate of $27.6 \%$ people in Nepal, who speak English as a second language. Current estimates indicate that $30 \%$ people speak English as a second language which counts to 8.7 million (Bolton \& BaconShone, 2020). Anecdotally, some linguists have estimated that around $40-50 \%$ of urban Nepalese are functionally literate in English (p. 56). In terms of popularity, education, and use, English, after Nepali, is the second most widespread language in Nepal, which is spoken by both literate and non-literate people at all socio-economic levels (Eagle, 1999). Because of the widespread use of English, it has become everybody's language or one of the local languages in Nepal (Giri, 2020b). It has become the chief lingua franca in the Nepalese society, overtaking Nepali, in crucial sectors like tourism, trade and business, education, science and technology, and most other economic sectors (Giri, 2020a). The contributing factors for the spread of English in Nepal from past to present include the entry and the settlement of European missionaries in Nepal, colonization of India by British Empire and its direct and indirect influence in Nepal, the recruitment and the retirement of the Nepalese British Army, the establishment of the Darbar School and Tri-Chandra College (their names themselves are hybrid) which adopted English as the language of education, British Council, American Embassy, Nepal English Language Teachers' Association (NELTA), business, research, tourism, technology, education (particularly private schools), mass media, and global cyber culture. Phyak (2012) mentioned that globalization and neoliberalism are the two key forces for accelerating the use of English in Nepal. With its rapid and systematic spread in Nepal, English is used not only as a medium of instruction in schools and universities but also

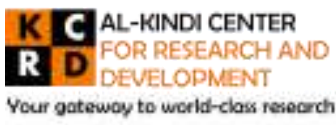

Published by Al-KindiCenter for Research and Development. Copyright (c) the author(s). This is an open access article under CC BY license (https://creativecommons.org/licenses/by/4.0/) 
as a subject to be taught and learnt. The provisions made by the Ministry of Education in its 2005 National Curriculum Framework for School Education to use Nepali, English, or both as the medium for school-level education and 2009 School Sector Reform Plan to teach English as a subject from grade one onwards provided the grounds for increasing the use of English in Nepal (Phyak, 2016). This policy was uncritically adopted without evaluating its dark side. Interestingly, the Ministry of Education "focuses on the English-as-the-medium-of-instruction policy to compete with private schools" (p. 211). With its increased use in speech and writing inside and outside the formal classrooms by the bilingual speakers, English has become more plural and hybrid. Because of its contact with the local languages, English has become a hybrid language today (Karn, 2006) as the globalization and the global spread of English proceed on. The hybridity which is a cross-category process (Pieterse, 1995) or double voiced discourse (Bakhtin, 1981) is produced by the tension between global discourses and local practices (Lee, 2006). The influence of the global English to the local languages, and vice versa gives rise to new hybrid language varieties (Graddol, 2000).

Despite its emergence as a postcolonial theoretical concept, hybridity is a colonial concept that "served certain interests, which were central to the colonial enterprise" (Prabhu, 2007, p. xii). With the British and American colonization over other countries and migration of English native speakers over other countries, the English language and culture came into contact with the local languages and cultures, which produced hybridity in languages and cultures. Hybridity, in this sense, implies "the creation of new transcultural forms within the contact zone produced by colonization" (Ashcroft et al., 2007, p. 108). Such contact zones are "circumscribed in time and space, but with elastic boundaries" (Bizzell, 1994, p. 166). In response to Rutherford's question, Homi Bhabha described that hybridity is not to trace two original moments from which the third emerges; rather hybridity itself is the "Third Space" which enables other positions to emerge (Rutherford, 1994). The notion of this third space created by the cultural exchange is what Kramsch (1993, p. 9) called "third culture in its own way." It means, the process of hybridity, whether linguistic or cultural, produces "something different, something new and unrecognizable, a new area of negotiation of meaning and representation" (p. 211). The new and different hybrid forms of Nepalese English, which exhibit the hybrid bicultural identity and bilinguals' creativity and provide local epistemologies, are the less focused area of research in Nepal. In this paper, our focus is particularly on the analysis of the lexical items and expressions of Nepalese English from the lens of hybridity. In the following section, we review both the theoretical and empirical literatures that provide basic grounds to this study.

\section{Literature Review}

The present paper hinges on three different but related theoretical ideas that inform this study: the notions of languages in contact popularized by Weinreich (1968), the bilinguals' creativity (B. Kachru, 1985) and the nativization first introduced by B. Kachru $(1982,1986)$ and further explained in Schneider's $(2003,2007)$ Dynamic Model. When two or more languages come into contact, they mutually influence each other and borrow lexical words (Weinreich, 1968). The result of language contact is what he referred to as "interference phenomena," which involves "those instances of deviation from the norms of either language which occur in the speech of bilinguals as a result of their familiarity with more than one language" (p. 1). Hybridity in English is caused by its contact with multiple languages and bilinguals' creativity. In the contact situations, the hybridity and deviations may be manifested in different levels of languages. Both Moag's (1992) Life Cycle of Non-native Englishes (cited in Kirkpatrick, 2007) and Schneider's (2003, 2007) Dynamic Model suggest that the emergence of new, hybrid varieties of English is deeply grounded in language contact situations. As long as the languages and cultures are in contact, they become more diversified and hybridized. Schneider (2016) explained that the intense presence and utility of English in the contact zones produce new types of hybrid linguistic usage, which Canagarajah (2013) referred to "codemeshing." B. Kachru (2011) further elaborated that the concept of hybridity in contact situations can be better understood by studying contact linguistics and contact literature.

Hybridity is not only the outcome of language contact but also the bilinguals' creativity, which refers to "those linguistic processes which are the result of competence in two or more languages" (B. Kachru, 1985, p. 20) and reflects "the blend of two or more linguistic textures and literary traditions that provides the English language with extended contexts of situation within which they are interpreted and understood" (B. Kachru, 1987, p. 127). In South Asian context, bilinguals' creativity refers to "creative uses of English in South Asia by those who are bilingual or multilingual, and who use English as one of the languages in their linguistic repertoire" (B. Kachru, 2011, p. 57). As the bilinguals have the competence in two or more languages, they can create "new meanings and innovations appropriate to the new cultural contexts" (Bolton, 2010, p. 458). The hybrid expressions are innovations that may convey the new meanings. B. Kachru (1985) described three essential approaches to the 
study of the bilingual's creativity: linguistic, literary, and pedagogical. In this article, we only discuss linguistic creativity which underpins linguistic hybridity.

Linguistic creativity refers to "a marked breaking or bending of rules and norms of language, including a deliberate play with its forms and its potential for meaning" (Carter, 2004, p. 9), "the breaking, re-forming, and transforming of established patterns" (Maynard, 2007, p. 3), "localized linguistic innovations" (B. Kachru, 2011, p. 123), "inventiveness in form," "innovations of meaning and of word creation in the Lexicon," "deviation and foregrounding," and "the departure from what is expected in language" (Wales, 2011, p. 95). Functionally, Rivlina (2020) claimed that linguistic creativity implies the "focus on the message for its own sake," (Jakobson, 1960, p. 365) which is the crux of Jakobson's poetic function, also known as "creative, imaginative, or aesthetic function" (Rivlina, 2020, p. 410). These ideas imply that linguistic creativity is the language user's ability to invent or innovate new words and expressions that may have new meanings and to deconstruct the previous rules, norms, and patterns. Different scholars see bilingual linguistic creativity either in a broad or a narrow way (Rivlina, 2020). In the broad sense, bilingual linguistic creativity is often applied to "all types of linguistic innovations and deviations induced by language contact, including various new and unconventional linguistic forms, sometimes the very practice of code-switching, codemixing, and borrowing" (p. 410) and in the narrow sense, it implies "dominated or determined by creative (poetic, aesthetic) function, focusing on the innovatively mixed linguistic form itself" (p. 410). In the case of linguistic creativity, B. Kachru (1985) focused on language mixing, contrastive discourse, interactional approaches, and contrastive linguistics.

In the multilingual contexts, English has the Janus-like two faces: nativization, the effect of English in a localized context, and Englishization, the effect on local languages in the same context (B. Kachru, 1996, 2011; Bolton, 2006). In the context of the Outer and Expanding Circles, contact between English and local languages has resulted in nativization of English and Englishization of indigenous languages (Y. Kachru, 2020). Besides these two Circles, even in the Inner Circle, English has undergone the process of nativization and resulted in localized forms of English (Matsuda, 2020). One of the strategies to nativize English is lexical borrowing. The borrowed forms are often combined with local ones to produce hybrid forms. Linguistic hybridization is a common nativization strategy advocated by B. Kachru (1986). The users of English deliberately nativize English according to the local contexts, which results in some kind of hybridity in English. Schneider $(2003,2007)$ elaborated the notion of nativization in his Dynamic Model as the most important, the most vibrant, the central phase of both cultural and linguistic transformation which is marked by heavy lexical borrowing for further cultural terms, phonological, phraseological and grammatical innovations, and is typified by new word-formation products, like derivations or compounds (hybrid), localized collocations and set phrases, varying prepositional usage, innovative assignments of verb complementation patterns to individual verbs, and alternative morphosyntactic behavior of certain, semantically defined word groups.

The history of English studies tended to emphasize the purity and homogeneity of English (Schneider, 2016) rather than its heterogeneity and hybridity in contact situations. Currently hybridity which can only exist in opposition to purity (Stockhammer, 2012) has become an increasingly fashionable term, most notably in the field of postcolonial literary studies (Ackermann, 2012). Postcolonial scholars, most prominently Edward W. Said, Gayatri Chakravorty Spivak, and Homi K. Bhabha attempted to problematize the representation of "the other" in literature as well as academia and thus developed a renewed interest in the hybrid (p. 11). In his novel Kanthapura, Rao (1938) expressed the idea of hybridity as "We cannot write like the English. We should not. We cannot write only as the Indians. We have grown to look at the large world as part of us" (p. vii). This perspective relates to hybridity in terms of convergence of visions when English is used in the pluralistic contexts and a linguistic consequence of this convergence results in formally distinct Indian variety of English (B. Kachru, 2011). In his first Journal article "The Indianness in the Indian English" (1965), B. Kachru defined hybrid (or mixed) formations as "those Indianisms which comprise two or more elements, and in which at least one element is from an Indian language and one from English" (p. 407). He described open set hybrid formations such as hybrid collocations, hybrid lexical sets, hybrid ordered series of words and hybrid reduplications, and closed set hybrid formations like suffixation. Tom McArthur was one of few scholars to name and describe the hybrid forms of English. In 1987, he represented different mixed or hybrid varieties of Englishes in his Circle of World Standard English (McArthur, 1987). He originally labelled such hybrid terms as "Anglo-hybrids" and described worldwide Anglo-hybridization as "a subject that scholars have yet to address in any detail" and professed that "the scale of such hybridization worldwide is staggering, and is likely to be a key geolinguistic issue in the early $21^{\text {st }}$ century" (McArthur, 1995, p. 2). His claim sounds true in that hybrid language, literature, and culture are one of the dominant areas of study worldwide today.

Lambert (2018) studied the nomenclature of hybrid Englishes and found Amerenglish to have coined in 1923, followed by Spanglish in 1933, Chinglish in 1936, Germenglish in 1936, Frenglish in 1937, and Swenglish in 1938. Other 5 new hybrid terms 
were added in the 1940s and 1950s; 15 terms in the 1960s; 41 terms in the 1970s; 48 terms in the 1980 s; 125 terms in the 1990s; 152 terms in the 2000s; and 88 terms from 2001 to 2016 (Lambert, 2018). He mentioned that the two-word compound term preceded the creation of the hybrid term, usually by many decades, for example, the term Chinese English dates back to 1840, while Chinglish only to 1936, Australian English dates from 1851, but Auslish only from 1991, Hungarian English from 1897, but Hunglish from 1978, Global English from 1962, but Globish from 1995. This is true in the case of the Nepali variety of English. The term Nepali English was used by Ramesh Shrestha in his article "Diglossomania in Nepali English" published in 1978 (Shrestha, 1983). Similarly, Tom McArthur used the term Nepalese English in 1987 as a South Asian Standard(izing) English (McArthur, 1987). Although Vishnu Singh Rai championed the term "Nenglish" in 2006 through his paper presentation in the International Conference of Nepal English Language Teachers' Association (NELTA) and article (Rai, 2006), Nenglish, Nepanglish, and Neplish were first recorded in 1999, 2000, and 2002, respectively (Lambert, 2018).

The hybridized Englishes are blended in a number of different levels based on whether there is an overlap of letters or phonemes, and whether either or both of the words are truncated (Lambert, 2018). The word "Nenglish," which blends Ne(pali) and (E)nglish, involves overlapping of "e," but truncation of only one of the terms. In the words like "Neplish," the blend between Nep(ali) and (Eng)lish, and "Nepanglish," the blend between Nepa(li) and (E)nglish, there is no overlap, but both etymons are truncated. The word "Nepenglish" blends Nep(ali) and English, in which there is no overlap, but only one etymon is truncated. In the colloquial term, this variety is also called "Nepangrezi," the blend between Nepa(li) and Angrezi (the Nepali term to refer to English), which share the letter "a" but truncation of only one of the terms. The word "Ninglish" blends N(epali) and (E)nglish, in which both etymons do not have the vowel letter "i" in the spelling, as in Binglish (Bengali English) and Dinglish (Dutch English). Lambert (2018) claimed that such peculiar forms result from a respelling of English to "Inglish" because spelling them with the original " $\mathrm{e}$ " of English does not give the correct pronunciation. The etymologies of all these terms are based on the country's name or the languages, for instance, Nenglish can be the blend between Nepal/Nepali and English and so is the case for other terms. In this sense, etymologically, Nenglish, Nepanglish, Nepenglish, Neplish, and Ninglish are not the slang words as Hinglish and do not suggest the influence of only the Nepali language on English because these terms can be interpreted in both ways: the blend between the country (Nepal) and the language (English), and between languages (Nepali and English). They simply denote the variety of English spoken in Nepal, that is, Nepal's English, whatever the mother tongue of the speakers is. Shrestha (1978, cited in Shrestha 1983) analyzed some samples of Nepali English and showed that the Nepalese writer of English tends to use a marked style, that is, use of a great deal of adjectives, longer sentences, uncommon words with the effect of learnedness and bombast, synonyms, and euphemisms. Brett (1999) first compiled a miniature glossary of Nepalese English lexical words and described how they are different from the Standard English. Similarly, Rai (2006) described some spoken and written forms of some Nepalese English lexical items and concluded that Nepali words are making entries in English and English suffixes are being attached to Nepalese words and vice versa. In his study on the nativization strategies adopted by creative writers in English literature in Nepal, Karn (2012) found that they produced hybrid words to exhibit cultural identities. Although these studies have focused on lexical items of Nepalese English, they have not been studied specifically from the lens of hybridity. However, their studies present some examples of hybridity in Nepalese English. In the following section, we describe what methodology we adopted to study the hybridity in Nepalese English.

\section{Methodology}

In order to study the hybrid lexical items and expressions of Nepalese English, we purposively selected two anthologies of stories, namely, Martyr and Other Stories written by Vishnu Singh Rai (2016a) and Arresting God in Kathmandu by Samrat Upadhyay (2018); two novels, namely, The Other Queen by Sheeba Shah (2018) and Palpasa Café (translated into English) by Narayan Wagle (2016); a travel essay A Day in the Kalaksetra Guwahaty, Assam (2016) and a memoir-like essay Reminiscing my Childhood Days (Ignorance of Bliss) (2012) by Govinda Raj Bhattarai; one essay Is Nepal Small?(2017) by Laxmi Prasad Devkota; another essay A Letter from Gautam Buddha to Ashoka (2017) by Krishnachandra Singh Pradhan; a travel essay Three Months in Austria (2016b) by Vishnu Singh Rai; an autobiography Atmabrittanta: Late Life Recollections (2017) by B.P. Koirala; an article I am the Nepali (2017) by CK Lal; one article and one news report from the English newspapers; some advertisements/banners; and diary entries. We read the sample texts, picked up hybridized forms, and analyzed them qualitatively. In what follows, we discuss the key results on hybridity.

\section{Results and Discussion}


The analysis and interpretation of lexical items and expressions collected from the sources mentioned above provides the evidence to support the claim that English used in Nepal is a hybrid language, which is discussed in the areas of affixation, reduplication, blending, compounding, neologisms, and calques in the following sections.

\subsection{Hybrid Affixation}

Nepalese English lexical words are formed by adding Nepali affixes to English words and vice versa, which produce hybridized words. The Nepali suffix $-j i$ is attached to the names and professions to show respect and closeness, for example, Michaelji, sirji, poetji (Rai, 2016a), and postman-ji (Upadhaya, 2018); -wala is attached to the nouns to denote the possessor, or the owner, for example, taxiwala, vanwala, and icecreamwala; and most interestingly, the Nepali plural suffix -haru is attached to the already plural English nouns, for example, childrenharu and furnitureharu, which is also reflected in Nepalese English words such as jewelries (Bhattarai, 2016; Rai, 2016a), evidences, offsprings (Shah, 2018), and luggages (Rai, 2016b). Such double pluralization is common in Nepalese English.

The English affixes which are attached to Nepali words to produce hybrid lexical words involve "-s/es" in the words like dokos "wicker baskets" (Rai, 2016a; Wagle, 2016), darbars "Palaces," andolens "movements" (Rai, 2016a), rajas "kings," pujas "prayers," sipahis "soldiers," and kalashes "pitchers" (Shah, 2018); the English apostrophic ('s) in the words such as guruji's will "the driver's will" (Rai, 2016a), and kaakaa's house "uncle's house" (Upadhyay, 2018); "-ic" in Brahmanic (Bhattarai, 2012); "-ed" in namasted "the Nepali greetings by joining two palms" (Rai, 2016a); "-ist" in Buddhist (Upadhyaya, 2018); "-an" in Teraian "inhabitant of the plain or lowland" (Rai, 2016b), "anti-" in anti-chhaupadi "against a menstrual taboo" (Budha, 2020), and "non-" in non-Nepali "one other than Nepali" (Devkota, 2017) and non-Gorkhali "other than the inhabitants of Gorkha or the brave Nepalese people" (Lal, 2017). Some words formed through hybrid affixation include andazification/ adkalization "guessing," Nepalization "influence of the Nepali language on other languages," Nepalized "made something Nepali-like," Nepalese "people having Nepali citizenship, " and Nepaliness "having the characteristics of Nepali."

\subsection{Hybrid Reduplication}

Hybrid reduplication is "a strategy used in cross-cultural texts, in order to provide an explanation to the non-English words, either in the form of word, clause, or a sentence to reflect the cultural baggage that the context has" (Jadoon, 2017, p. 12). Nepalese writers make unique way of reduplication by mixing words from two languages which have "an 'identical' lexical meaning..." (B. Kachru, 1975, p. 65). Some hybrid reduplicated words in Nepalese English include bhola (innocent); buhari 'daughter-in law;' the guruji, the bus driver; Jana Yuddha 'People's War;' khainee 'chewing tobacco;' Shaheed (Marytr) (Rai, 2016a); mama 'mother's brother;' and sanima "step mother" (Rai, 2016b); stupid ooloo (Wagle, 2016); Jaa, go; Bhann. Tell me. Speak; and Bussa, sit (Shah, 2018). In these hybrid expressions, either Nepali or English expressions are redundant. However, they become comprehensible to the Nepalese readers.

\subsection{Hybrid Blending}

In Nepalese English, new hybrid words are formed by two words from Nepali or Nepal and English. As described above, the name given to the Nepali variety of English itself is the blended word, for instance, Nenglish, Nepanglish, Nepenglish, Neplish and Ninglish; all of which are formed by blending the two words "Nepali or Nepal" and "English." Other hybrid blended words include Ranarchy, the blending from "Rana" (cruel ruler in Nepal in the past) and "anarchy," and kubility, which blends "khubi" (skill) and "ability." Such blending maximizes linguistic economy and exhibits bilinguals' creativity.

\subsection{Hybrid Compounding}

Among the hybrid compounds, Weinreich $(1968$, p. 52) distinguished those in which "the stem is transferred and a derivative affix produced" and those in which "the stem is indigenous and an affix transferred." In the similar way, B. Kachru (1975, p. 66) categorized hybrid compounds as hybrid with "South Asian item as 'head' and as 'modifier'." Several compound words in Nepalese English are hybrids which consist of two types of structures: Noun-Noun type and Adjective-Noun type. In the hybrid compounds, either the Nepali word or the English word functions as the head.

\subsubsection{Nepali or Local Word as Head}

In this group, the Nepali or the local word is the head and the English word is the modifier. In terms of the position of the components, the head-modifier relationship is further divided into the three types: Noun-Noun type, Adjective-Noun type, and -ing Head type.

\subsubsection{Noun-Noun Type}


In this type, the Nepali noun functions as the head and the English noun functions as the modifier, e.g. neighbourhood bhatti "a nearby place where local wine is made" (Upadhyay, 2018), tomato achar "pickle made from tomatoes, " painter babu "a respect or affectionate address to the painter, " mutton sukuti "dried meat of he-goat, " cotton batti "cotton wick" (Wagle, 2018), gold kalash "water-vessel made of gold," gold mohars "Nepali coins made of gold," doctor saheb "a respect word to address the doctor," (Shah, 2018) and valley bund "strike in the valley" (Rai, 2016a).

\subsubsection{Adjective-Noun Type}

In this type of hybrid compounds, the Nepali or the local word is the noun which functions as the head and the English word is an adjective which functions as the modifier, for example, skinny bahun "a very thin person from the Brahmin caste, " black daal "black pulse" (Wagle, 2018), mighty angrez "a powerful Englishman," royal vaidyas " personal Ayurvedic doctors of the Royal family," local jaand "local liquor made from the fermented rice or other grains," local aila "a kind of liquor from the Newari community," black-uniformed sipahis "the black dressed soldiers" (Shah, 2018), colourful lungi "a colourful garment wrapped around the waist, usually below the belly, " real gunda "real hooligan," simple dal-bhat "general Nepali dish" (Rai, 2016a), architectural smarak "a memorial with the attractive designing" (Bhattarai, 2016), and half-dhoti "a small piece of cloth wrapped under the waist" (Koirala, 2017).

\subsubsection{3 -ing Head Type}

In this third category, some restricted number of hybrid compounds are found in Nepalese English in which the -ing form functions as the modifier, for example, wedding doli "a wooden palanquin to carry a bride during the wedding" (Upadhyay, 2018), and fumbling bahuns "people from the Brahmin caste who are awkward or hesitant to do something" (Shah, 2018).

\subsubsection{Nepali or Local Word as Modifier}

In this group, the Nepali or the local word functions as the modifier and the English word as the head. This group has been further subcategorized into Noun-Noun type and Adjective-Noun type.

\subsubsection{Noun-Noun Type}

This is the most productive and common compounds in Nepalese English. In this group, both words are nouns but they function differently. The English word functions as the head and the Nepali or local word functions as the modifier, for example, kuirey journalist "a British journalist," tandoori chicken "chicken roasted in a traditional oven called tandoor," puja room "a prayer room, " rupee notes "bills or banknotes of Nepali currency," puja ceremony "a prayer ceremony," Tamang girl "a girl from the Tamang ethnic group of Nepal" (Upadhyay, 2018); khukuri knife "a national knife of Nepal" (Bhattarai, 2016; Upadhyay, 2018); patuka belt "a long cloth tied around the waist as a belt," khukuri pin "cufflinks to put with a cap," Bhai Tika festival "a Hindu festival in which the brothers receive tika from their sisters," Samadhi site "a place of cremation" (Bhattarai, 2016); Dashain holidays "holidays given in the Dashain festival," bahun bird "a child from the Brahmin caste," firangee soldiers "British soldiers," raksha thread "sacred thread worn for protection," Indrajatra tale "a story of celebrating the Indrajatra festival of Nepal," Gorkha crown "the crown worn by the king or queen of the Gorkha kingdom" (Shah, 2018); angrezi book "English book," Brahmin son "a son of the Brahmin caste" (Bhattarai, 2012); chhau sheds "cattle sheds where Hindu women and girls are put during the period of menstruation," sati traditions "the ancient Hindu tradition in which a widow burns herself on her husband's pyre" (Budha, 2020); Panchayat curriculum "curriculum made during the direct rule of the king in Nepal," khas-Arya group "hill, Hindu high caste people" (Kunwar, 2020); and Bahun tradition "the tradition or ritual followed by the Brahmin caste," Kshatriya obligations "obligations for people belonging to Khas Chhetri caste to follow, who were the military and ruling class of the ancient Hindu society" (Koirala, 2017). Similarly, the hybrid compounds formed by Devkota (2017) include peepal tree "a sacred tree in the Hindu culture which is best for oxygen," Nepali air, Nepali heart, Nepali soil and Nepali sky, and by Pradhan (2017) include Bodhi tree "wisdom bo tree."

\subsubsection{Adjective-Noun Type}

In this type, the Nepali or local word is an adjective which functions as a modifier and the English word is a noun that functions as a head, for instance, Gaijatre cows "cows to be worshipped at Gaijatra festival" (Shah, 2018) and Buddhist temple "temple of Buddhist religion" (Upadhyay, 2018).

\subsection{Hybrid Neologisms}


Neologisms are newly coined words which are not always novel but are sometimes based on existing words. They generally "express the need to identify a new concept or idea" (Anesa, 2019, p. 38) or are used to convey the different meaning. Creative Nepalese people have coined some new words on analogy with "Kathmandu," the capital city of Nepal as if -mandu is a suffix to those words, e.g. woodmandu, foodmandu, maskmandu and clickmandu. Similarly, Nepalese people have coined a new word Kaliwood/Kallywood/Kollywood on analogy of Hollywood and Bollywood to refer to the Nepali film industry in Kathmandu. All these coined words are hybrid in nature.

\subsection{Hybrid Calques}

The loan translations are etymologically hybrid which borrow the meaning, structure, and one of their components from English and the other component from the local language (Christina, 2012). Nepalese English uses calques, or loan translations from the Nepali language. The proverb husband-wife's quarrel is like hay-fire (Rai, 2016a) "husband and wife's quarrel subsides in a short time" or "The quarrel between husband and wife is temporary" is hybrid in that the given proverb is in English but it is the direct word-for-word translation from Nepali. The other expressions from Shah (2018) such as what has happened has happened "let bygones be bygones," even the walls have ears "be careful what you say as people may be eavesdropping," once a thief always a thief "once you earn bad name, it will always be with you," and from Upadhyay (2018) such as a bull without horns can't call himself sharp "an empty vessel makes much noise" are all literal translations of the Nepali proverbs. They are the English expressions in the structure of the Nepali language which conveys the Nepalese cultural meanings.

\section{Conclusion and Implications}

In this article, we have analyzed the hybrid expressions of Nepalese English which indicate that linguistic and cultural hybridity is "our identity and destiny" (B. Kachru, 2011, p. 28) or "a fact of life" (Kanno, 2007, p. 63) and a symbol of linguistic co-existence in the puricentric societies in Nepal. The hybrid language forms represent national identities, reflect the power of the writers to describe and correspond to a particular ecology from within sociolinguistics of the region, and describe their contact with sociocultural and psycholinguistic realities (Rajashanthan, 2016). They are the creative aspects of uses of English which are misinterpreted or neglected due to the undue emphasis given to interlanguage and fossilization, which B. Kachru (1990) referred to as 'leaking' paradigms. They reflect the dynamics of cross-cultural and nativized or localized creativity in Nepalese English. In the linguistically and culturally heterogeneous classrooms, hybrid language practices serve as the central mediation tools which mediate students' learning (Gutiérrez et al., 1999b). In a Bakhtian (1981) sense, hybridity increases the possibility of dialogue, and, thus, the possibility of collaboration and learning (Gutiérrez et al., 1999a). In this sense, hybridity is "a resource for building collaboration and promoting literacy learning" (p. 88), serves as the building block of third space, or zone of proximal development (Gutiérrez et al., 1999b), and allows incidental learning and unfocused language acquisition (Rivlina, 2020). Hybrid language practices help the learners to move from actual developmental level to the potential developmental level by enhancing their mutual understanding and a joint collaborative activity. They serve as scaffolding for the learners' linguistic, social, and cognitive development since the use of hybrid English makes the learners easy to communicate with their teachers and solve different problems. Schools are the contact zones where different languages and cultures meet, clash, and grapple with each other and the interaction in such zones gives birth to hybrid forms of knowledge, texts, and codes which may resist homogeneity and domination (Canagarajah, 1999). The hybrid language practices challenge current English-only policies that privilege one particular language and minimize learning, stimulate joint participation and learning for all learners (Gutiérrez et al., 1999a), foster language and literacy development (Gutiérrez et al., 1999a; Gutiérrez et al., 1999b), and create a community of practice. The learners do not have to stick to the normative scripts, practices, and participation framework. They can utilize their bilingual or multilingual repertoires to produce hybrid forms that express typical meaning.

Hybrid language practices are the systematic, strategic, affiliative, and sense-making processes among those who share the code (Gutiérrez et al., 1999a). They strategically incorporate the local knowledge, cultures, and beliefs of the home and the school and serve as a bridge to connect both. At schools, the teacher and children consciously and strategically utilize their own linguistic repertoires and create new contexts of development (Gutiérrez et al., 1999b). Therefore, hybrid language practices are always present, although they are not always legitimized and utilized in formal learning contexts (Gutiérrez et al., 1999b). They have transformed the monolingual/monolithic classroom environments into the more inclusive, bilingual or multilingual ones. They may break the students' silence since they communicate with their teachers and peers using the hybrid English. They may increase the students' participation in the classroom. The students' increased participation, interaction and communication, and collaboration facilitate language learning. In addition, the hybridized texts, both linguistically and culturally, are easier for the students to comprehend because such texts activate their already established familiar schematic knowledge (Alptekin 2002, 2006) and facilitate language learning. Both the nativized or hybridized English and hybrid academic texts are the suitable alternative made by the periphery subjects for their communicative and ideological conflicts in using 
English (Canagarajah, 1999). Students and teachers can also use linguistic hybridization as a strategy to nativize English in the local contexts, exercise their bilingual linguistic creativity, reduce their linguistic anxiety, and to maximize the linguistic economy, allowing them to use one hybrid word to convey the same meaning, rather than using more words from the same language (Lee, 2013). Therefore, speakers of English in the periphery countries intentionally and strategically hybridize English and English texts in their own terms according to the local needs and interests.

If we slightly adapt Achebe's (1965) view in the Nepalese context, we can say that the English language to carry the weight of our Nepalese experience, the native variety in its unchanged form is incapable of serving that purpose. It should be a new hybrid English which "now combines global and local so a blend of different tastes can only satisfy the English language needs of the time" (Bhattarai \& Gautam, 2008, p. 14). In the pluralistic Nepalese societies, the hybridity is the unavoidable phenomenon which needs to be duly considered in policy formulation, production of materials, and pedagogy. This study limits to only the hybridity in lexical items and proverbs. Further research can be conducted on hybridity at the phonological, semantic, syntactic, and discourse levels.

\section{Funding}

This research received no external funding. It was conducted with the self-initiation and self-effort of the authors.

\section{Acknowledgements}

The authors are grateful to Prof. Dr. Vishnu Singh Rai and Dr. Prem Phyak for their constructive feedback and suggestions. Additionally, the authors would like to thank the anonymous reviewers for their suggestions to revise the manuscript and bring it to the present form.

\section{Conflicts of Interest}

No potential conflict of interest was reported by the authors.

\section{References}

[1] Achebe, C. (1965). English and the African writer. Transition, 18, 27-30.

[2] Ackermann, A. (2012). Cultural hybridity: Between metaphor and empiricism. In P. W. Stockhammer (Ed.), Conceptualizing cultural hybridization: A transdisciplinary approach (pp. 5-25). Springer.

[3] Alptekin, C. (2002). Towards intercultural communicative competence in ELT. ELT Journal, 56(1), 57-64.

[4] Alptekin, C. (2006). Cultural familiarity in inferential and literal comprehension in L2 reading. System, 34, 494-508. https://doi.10.1016/j.system.2006.05.003

[5] Anesa, P. (2019). Lexical innovation in world Englishes: Cross-fertilization and evolving paradigms. Routledge.

[6] Ashcroft, B., Griffiths, G., \& Tiffin, H. (2007). Post-colonial studies: The key concepts. Routledge.

[7] Awasthi, L. D. (2020, February 29). ăngreji bhāsāle paramparōmāthi ăcha. Kantipur National Daily. https://ekantipur.com/news/2020/02/19/158212312197956294.html

[8] Bakhtin, M.M. (1981). The dialogic imagination: Four essays (C. Emerson, \& M. Holquist, Trans.). University of Texas Press.

[9] Bhattarai, G. R., \& Gautam, G. R. (2008). More eclectic and interdisciplinary approach to English: Call for time. Journal of NELTA, 13, 1114.

[10] Bhattarai, G.R. (2012). Reminiscing my childhood days. Journal of Nepalese Literature, Art and Culture, 7(1-2), $155-164$.

[11] Bhattarai, G.R. (2016). A day in the Kalaksetra of Guwahaty. In J.R. Awasthi, G.R. Bhattarai, \& V.S. Rai (Eds.), Readings for the new horizons (pp. 305-311). MK Publishers and Distributors.

[12] Bizzell, P. (1994). "Contact Zones" and English studies. College English, 56(2), 163-169.

[13] Bolton, K. (2006). World Englishes today. In B.B. Kachru, Y. Kachru, \& C.L. Nelson (Eds.), The handbook of world Englishes (pp. 240-269). Blackwell Publishing.

[14] Bolton, K. (2010). Creativity and world Englishes. World Englishes, 29(4), 455-466. https://doi.org/10.1111/j.1467-971X.2010.01674.x

[15] Bolton, K., \& Bacon-Shone, J. (2020). The statistics of English across Asia. In K. Bolton, W. Botha, \& A. Kirkpatrick (Eds.), The handbook of Asian Englishes (pp. 49-80). WILEY Blackwell.

[16] Brett, L. (1999). Standard English? Wecome to Nepal. Journal of NELTA, 4, 85-92.

[17] Budha, D.B. (2020, January 4). We don't follow Chhaupadi [News report]. Republica, p. 4.

[18] Canagarajah, A.S. (1999). Resisting linguistic imperialism in English teaching. Oxford University Press.

[19] Canagarajah. S. (2013). Translingual practice: Global Englishes and cosmopolitan relations. Routledge.

[20] Carter, R. (2004). Language and creativity: The art of common talk. Routledge.

[21] Central Bureau of Statistics. (2014). Population monograph of Nepal (Volume II). Author.

[22] Christina, S. (2012). Hybridization in language. In P.W. Stockhammer (Ed.), Conceptualizing cultural hybridization: A transdisciplinary approach (pp. 133-157). Springer.

[23] Crystal, D. (2003). English as a global language. Cambridge University Press. 
[24] Devkota, L.P. (2017). Is Nepal small? In G.R. Bhattarai (Ed.), Interdisciplinary readings (pp. 227-234). Oriental Publication House Pvt. Ltd.

[25] Eagle, S. (1999). The language situation in Nepal. Journal of Multilingual and Multicultural Development, 20(4/5), 272-327. https://doi.org/10.1080/01434639908666382

[26] Giri, R.A. (2020a). Nepali English. In K. Bolton, W. Botha, \& A. Kirkpatrick (Eds.), The handbook of Asian Englishes (pp. 317-336). WILEY Blackwell.

[27] Giri, R.A. (2020b, October 30). English is one of the local languages in Nepal [Interview]. ELT Choutari, a professional blog. http://eltchoutari.com/2020/10/english-is-one-of-the-local-languages-in-nepal-dr-giri/

[28] Graddol, D. (2000). The future of English? The British Council.

[29] Gutiérrez, K.D., Baquedano-López , P., \& Tejeda, C. (1999b). Rethinking diversity: Hybridity and hybrid language practices in the third space. Mind, Culture, and Activity, 6(4), 286-303. https://doi.org/10.1080/10749039909524733

[30] Gutiérrez, K.D., Baquedano-López , P., Alvarez, H.H., \& Chiu, M.M. (1999a). Building a culture of collaboration through hybrid language practices. Theory into Practice, 38(2), 87-93. https://doi.org/10.1080/00405849909543837

[31] Jadoon, N.K. (2017). Pakistanization of English in Kamila Shamshie's Kartography. International Journal of English Language and Linguistics Research, 5(4), 1-17.

[32] Jakobson, R. (1960). Concluding statement: Linguistics and poetics. In T. A. Sebeok (Ed.), Style in language (pp. 350-377). Harvard University Press.

[33] Kachru, B. B. (1987). The bilingual's creativity: Discoursal and stylistic strategies in contact literature. In L. E. Smith (Ed.), Discourse across cultures: Strategies in world Englishes (pp. 125-140). Prentice Hall.

[34] Kachru, B.B. (1965). The Indianness in Indian English. Word, 21(3), 391-410.

[35] Kachru, B.B. (1975). Lexical innovations in South Asian English. International Journal of the Sociology of Language, 4, 55-74. https://doi.org/10.1515/ijsl.1975.4.55

[36] Kachru, B.B. (1982). The other tongue: English across cultures. University of Illinois Press.

[37] Kachru, B.B. (1985). The bilinguals' creativity. Annual Review of Applied Linguistics, 6, 20-33.

[38] Kachru, B.B. (1986). The alchemy of English: The spread, functions and models of non-native Englishes. Pergamon.

[39] Kachru, B.B. (1990). World Englishes and applied linguistics. World Englishes, 9(1), 3-20.

[40] Kachru, B.B. (1996). World Englishes: Agony and ecstasy. The Journal of Aesthetic Education, 30(2), 135-155.

[41] Kachru, B.B. (2011). Asian Englishes beyond the canon. Hong Kong University Press.

[42] Kachru, Y. (2020). Speaking and writing in world Englishes. In C.L. Nelson, Z.G. Proshina, \& D.R. Davi (Eds.), The handbook of world Englishes (pp. 349-367). Wiley Blackwell.

[43] Kanno, Y. (2007). ELT policy directions in multilingual Japan. In J. Cummins \& C. Davison (Eds.), International handbook of English language teaching (pp. 63-74). Springer.

[44] Karn, S.K. (2006). English: Then, now and in the days ahead. Journal of NELTA, 11, 73-79.

[45] Karn, S.K. (2012). This is how I can write: Towards Nepalese English literature. Journal of NELTA, 17, 26-39.

[46] Kirkpatrick, A. (2007). World Englishes: Implications for international communication and English language teaching. Cambridge University Press.

[47] Koirala, B.P. (2017). Atmabrittanta: Late life recollections (K.M. Dixit, Trans.). In G.R. Bhattarai (Ed.), Interdisciplinary readings (pp.136150). Oriental Publication House Pvt. Ltd.

[48] Kramsch, C. (1993). Context and culture in language teaching. Oxford University Press.

[49] Kunwar, N. (2020, January 13). Dump the old curriculum. The Kathmandu Post, p. 6.

[50] Lal, C.K. (2017). I am the Nepali. In G.R. Bhattarai (Ed.), Interdisciplinary readings (pp.236-244). Oriental Publication House Pvt. Ltd.

[51] Lambert, J. (2018). A multitude of "lishes": The nomenclature of hybridity. English World-Wide, 39(1), 1-33. https://doi.org/10.1075/eww.00001.lam

[52] Lee, J. S. (2013). Hybridizing medialect and entertaining TV: Changing Korean reality. In R. Rubdy \& L. Alsagoff (Eds.), The global-local interface and hybridity: Exploring language and identity (pp. 170-188). Multilingual Matters.

[53] Lee, J.S. (2006). Linguistic constructions of modernity: English mixing in Korean television commercials. Language in Society, 35(1), https://doi.org/10.1017/S0047404506060039

[54] Matsuda, A. (2020). World Englishes and pedagogy. In C.L. Nelson, Z.G. Proshina, \& D.R. Davi (Eds.), The handbook of world Englishes (pp. 686-702). Wiley Blackwell.

[55] Maynard, S.K. (2007). Linguistic creativity in Japanese discourse. John Benjamins Publishing Company.

[56] McArthur, T. (1987). The English languages? English Today, 3(3), 9-13. https://doi.org/10.1017/S0266078400013511

[57] McArthur, T. (1995). The Anglo-hybrids. English Today, 44, 2. https://doi.org/10.1017/S0266078400008518

[58] Phyak, P. (2012, July 9). The English language in Nepal. Creativity. The Kathmandu Post, p. III.

[59] Phyak, P. (2016). Local-global tension in the ideological construction of English language education policy in Nepal. In R. Kirkpatrick (Ed.), English language education policy in Asia (pp. 199-218). Springer.

[60] Pieterse, J.N. (1995). Globalization as hybridization. In M. Featherstone, S. Lash, \& R. Robertson (Eds.), Global modernities (pp. 45-68). Sage.

[61] Prabhu, A. (2007). Hybridity: Limits, transformations, prospects. State University of New York Press.

[62] Pradhan, K.S. (2017). A letter from Gautam Buddha to Ashoka. In G.R. Bhattarai (Ed.), Interdisciplinary readings (pp.247-256). Oriental Publication House Pvt. Ltd. 
[63] Rai, V. S. (2006). English, Hinglish and Nenglish. Journal of NELTA, 11, 34-39.

[64] Rai, V.S. (2016a). Martyr and other stories. Oriental Publication.

[65] Rai, V.S. (2016b). Three months in Austria. In J.R. Awasthi, G.R. Bhattarai, \& V.S. Rai (Eds.), Readings for the new horizons (pp. 277-289). MK Publishers and Distributors.

[66] Rajashanthan, S.S. (2016). Nativization of English by Jaffna writers. International Journal of Management and Applied Science, 2(1), 2733.

[67] Rao, R. (1938). Kanthapura. Hind Pocket Books (P) Ltd.

[68] Rivlina, A. (2020). Bilingual language play in world Englishes. In C.L. Nelson, Z.G. Proshina, \& D.R. Davis (Eds.), The handbook of world Englishes (pp. 407-429). Wiley Blackwell.

[69] Rutherford, J. (1994). The third space: Interview with Homi Bhabha. In J. Rutherford (Ed.), Identity, community, culture, difference (pp. 207-221). Lawrence and Wishart Limited.

[70] Schneider, E.W. (2003). The dynamics of new Englishes. From identity construction to dialect birth. Language, 79(2), $233-281$.

[71] Schneider, E.W. (2007). Postcolonial English: Varieties around the world. Cambridge University Press.

[72] Schneider, E.W. (2016). Hybrid Englishes: An exploratory survey. World Englishes, 1-16. https:/doi.org/ 10.1111/weng.12204

[73] Shah, S. (2018). The other queen. Sangri la Pustak Pvt.Ltd.

[74] Shrestha, R. (1983). English as a second language/English as a foreign language distinction: Its pedagogy and the Nepalese context. Contributions to Nepalese Studies, 11(1), 45-59.

[75] Stockhammer, P.W. (2012). Questioning hybridity. In P.W. Stockhammer (Ed.), Conceptualizing cultural hybridization: A transdisciplinary approach (pp. 1-3). Springer.

[76] Upadhyay, S. (2018). Arresting god in Kathmandu. Rupa Publications India Pvt. Ltd.

[77] Wagle, N. (2016). Palpasa Café (B. Sangruala, Trans.). Publication Nepa laya.

[78] Wales, K. (2011). A dictionary of stylistics. Routledge.

[79] Weinreich, U. (1968). Languages in contact: Findings and problem. Mouton Publishers. 